\title{
Hypotrichosis simplex of the scalp
}

INSERM

\section{Source}

INSERM. (1999). Orphanet: an online rare disease and orphan drug data base.

Hypotrichosis simplex of the scalp. ORPHA:90368

Hypotrichosis simplex of the scalp (HSS) is characterized by diffuse progressive hair loss that is confined to the scalp. 